\title{
Luis Gerardo Díaz Núñez, La Teología de la liberación latinoamericana hoy
}

Mexico, CIALC-UNAM, 2009, 382 p.

Luis Martínez Andrade

\section{(Q) OpenEdition}

Journals

Édition électronique

URL : http://journals.openedition.org/assr/22933

DOI : $10.4000 /$ assr.22933

ISSN : $1777-5825$

Éditeur

Éditions de l'EHESS

Édition imprimée

Date de publication : 31 décembre 2011

Pagination : 240

ISBN : 9782713223273

ISSN : 0335-5985

\section{Référence électronique}

Luis Martínez Andrade, «Luis Gerardo Díaz Núñez, La Teología de la liberación latinoamericana hoy », Archives de sciences sociales des religions [En ligne], 156 | octobre-décembre 2011, document 156-85, mis en ligne le 16 février 2012, consulté le 21 septembre 2020. URL : http://journals.openedition.org/ assr/22933 ; DOI : https://doi.org/10.4000/assr.22933

Ce document a été généré automatiquement le 21 septembre 2020.

(c) Archives de sciences sociales des religions 


\title{
Luis Gerardo Díaz Núñez, La Teología de la liberación latinoamericana hoy
}

Mexico, CIALC-UNAM, 2009, 382 p.

\author{
Luis Martínez Andrade
}

\section{RÉFÉRENCE}

Luis Gerardo Díaz NÚÑEZ, La Teología de la liberación latinoamericana hoy, Mexico,

CIALC-UNAM, 2009, $382 \mathrm{p}$.

1 Après la chute du mur de Berlin, l'effondrement du socialisme réel, la déclaration de la fin de l'histoire et la victoire du libre marché, qui oserait mettre en question l'actuel paradigme hégémonique? Où se trouvent les utopies, les projets alternatifs? La théologie de la libération est-elle morte aussi ? Pour comprendre la reconfiguration et la pertinence de ce courant théologique, Luis Gerardo Díaz Núñez, chercheur à l'Université Nationale Autonome du Mexique, nous présente dans son dernier ouvrage les continuités, les changements et les nouvelles inquiétudes des théologiens latinoaméricains de la libération. Composé de quatre chapitres, ce livre essaie de répondre à certaines questions telles que : que s'est-il passé avec cette théologie depuis les années 90 ? Quels sont ses nouveaux défis? Quel est son futur dans un contexte mondialisé ?

2 Le premier chapitre, América Latina ante el neoliberalismo y la globalización, rend compte de l'actuel contexte au sein duquel la théologie de la libération (TL) doit faire face aux effets politiques, économiques, culturels et sociaux de l'économie de marché. Il va sans dire que l'Amérique latine n'est pas une entité homogène, donc sa diversité culturelle et ethnique est un élément non-négligeable. Pourtant, l'auteur considère les nombreuses coïncidences que lui permettent de saisir les pays latino-américains comme un espace commun où l'augmentation de la pauvreté, du chômage et de la violence est devenue une tendance généralisée. Certes, l'Amérique latine n'est pas le 
continent le plus pauvre de la planète, mais il est le plus polarisé car les $10 \%$ les plus aisés de la population, détiennent $60 \%$ des richesses, tandis que les $10 \%$ les plus pauvres s'en partagent seulement $2 \%$ (p. 44). En ce sens, Díaz Núñez avertit que le capitalisme - en tant que régime "trans-séculaire» - utilise le processus de mondialisation comme un véhicule afin de consolider des structures de domination dans cette région périphérique.

3 Il en va ainsi de l'impérialisme (en tant que catégorie d'analyse sociale) : l'auteur rend et met en valeur le rôle des États-Unis dans les projets de privatisation et de militarisation du continent. Parmi les séquelles néfastes que l'auteur dénonce dans le domaine politique, on trouve la défiance croissante vis-à-vis des façons traditionnelles de faire la politique. La crise de la légitimité et de la représentativité ou la démission du Frei Betto de l'administration de "Lula " montrent le manque de soutien, dont souffrent des gouvernements dits de gauche (p. 57). Au niveau économique, les multinationales et le fleurissement des «maquiladoras» produisent un impact frappant sur la vie quotidienne des habitants et des peuples: 227 millions des personnes vivent au-dessous du seuil de pauvreté. Quant à l'aspect culturel, il relève l'homogénéisation des modèles, des images et des imaginaires qui sont modifiés et remaniés par le canon nord-américain. C'est dans ce nouveau contexte que la TL actualise son locus théorique et pratique sans omettre, bien évidement, son «option préférentielle en faveur des pauvres ».

4 À partir des années quatre-vingt-dix, la TL a élargi son éventail à de nouvelles préoccupations dont l'écologie, les cultures indigènes, les femmes, l'altermondialisation sont plus visibles. La création du Forum Social Mondial à Porto Alegre en 2001 est l'un des résultats de cette reconfiguration.

Dans le deuxième chapitre, La religión en el pensamiento actual y su impacto en América Latina, l'auteur aborde la présence du phénomène religieux dans la réalité sociale de l'Amérique latine. La fonction sociale de la religion est analysée depuis la perspective des sociologues de la religion tels que François Houtart, Danièle Hervieu-Léger et José María Mardones afin d'exprimer le caractère dynamique de celle-ci. Or, la religion en tant que relation sociale (p. 175) entraîne diverses conceptions du sacré, du politique et du social. En ce sens, Díaz Núñez nous propose une typologie des religiosités en Amérique latine, à savoir: a- une religiosité de l'élite caractérisée par une vision individualiste, qui est animée par les couches privilégiées et par les secteurs conservateurs de l'Église ; b- une religiosité populaire liée aux rites, où l'émotion et la fête sont présentes et ; c- une religiosité des pratiques informelles dont le new age ou les autres courants comme le néo-pentecôtisme sont des exemples importants dans un contexte de pluralisme religieux.

6 Utopía y esperanza cristiana en América Latina, troisième chapitre de cet ouvrage, propose une reconsidération de la force de l'utopie et de l'espérance comme éléments clés de l'imaginaire latino-américain. À ce propos, l'auteur s'appuie notamment sur les réflexions et les travaux d'Ernst Bloch, de Franz Hinkelammert, d'Horacio Cerutti et de Fernando Ainsa afin de déployer les différents projets d'utopie. D'après lui, du fait que l'utopie est une composante à part entière de l'humain, elle n'est pas homogène. Par conséquent, nous observons deux côtés de l'utopie, son côté libérateur et son côté conservateur.

7 D'autre part, Díaz Núñez développe le lien entre l'utopie et la société dans la démarche de la théologie de la libération, en montrant les engagements pastoraux et politiques de 
ses principaux animateurs, dans la vie sociale latino-américaine. Malgré la persécution et la répression dont souffrent les théologiens (p. 234), ceux-ci ne cessent pas de dénoncer la dynamique sacrificielle du système.

8 Le dernier chapitre, La teología de la liberación latinoamericana: desarrollos recientes, est consacré à l'actuel contexte dans lequel la TL doit évoluer, c'est-à-dire au cadre des nouveaux paradigmes qui ont permis à la TL d'élargir ses réflexions théologiques et sociales. Ceci explique le développement de nouveaux courants en son sein, tels que la théologie écologique de la libération (L. Boff), la théologie féministe latino-américaine (I. Gebara et E. Tamez), la théologie indigène (E. Lopez), la théologie afro-latinoaméricaine (A. Kasanda) et la théologie interculturelle (R. Fornet-Betancourt et J.J. Tamayo).

9 En utilisant l'herméneutique analogique (M. Beuchot) comme méthode pour mieux comprendre l'histoire de la pensée latino-américaine, Díaz Núñez conclut sa recherche en nous proposant la thèse selon laquelle « la théologie de la libération reste, jusqu'à nos jours, une structure de conscience critique et utopique » (p. 355). Selon l'auteur, en dépit du fait que la TL n'a pas la même diffusion ou publicité que dans les décennies 60 ou 70 et tant que les conditions d'exclusion et de marginalisation sociale existeront, cette théologie continuera à porter son message de dénonciation prophétique.

10 En somme, le texte que nous offre Díaz Núñez est pertinent pour les recherches en rapport à cette théologie, mais il se distingue plus largement par son effort de mettre en valeur les défis, les contradictions et les projets de ce courant de la pensée sociale et religieuse latino-américaine. 